\title{
Participación en el sector no agropecuario en el México rural: una perspectiva de género
}

\author{
Jorge Mora-Rivera ${ }^{\star}$ \\ Marlen Martínez Domínguez ${ }^{*}$ \\ José Luis Jaramillo Villanueva ${ }^{* \star \star}$ \\ María de los Ángeles Chávez Alvarado ${ }^{\star \star \star \star}$
}

\begin{abstract}
Los hogares rurales diversifican sus ingresos como estrategia para minimizar los riesgos, reducir la variabilidad y asegurar un nivel mínimo de ingreso. Con información panel de la Encuesta Nacional a Hogares Rurales de México, el presente estudio examina, bajo una perspectiva de género, los factores que determinan la participación en el sector no agropecuario. Los resultados señalan que en las ocupaciones asalariadas no agropecuarias, los hombres participan con menores niveles de escolaridad y la condición de indígena limita la incorporación de ambos géneros. En actividades no agropecuarias por cuenta propia son esenciales la riqueza acumulada del hogar y los servicios financieros, de comunicación y transporte.
\end{abstract}

Palabras clave: Género. Empleo no agropecuario. Hogares rurales. México.

\footnotetext{
* Tecnológico de Monterrey, Ciudad de México, México (jjmora@itesm.mx).

** CONACYT-Centro de Investigación e Innovación en Tecnologías de la Información y Comunicación (INFOTEC), Aguascalientes, México (marlen.martinez@infotec.mx).

${ }^{* \star \star}$ Colegio de Postgraduados, Puebla, México (jjaramil301@yahoo.es).

**** Desarrollo y Alimentación Sustentable A. C., Ciudad de México, México (angeleschavez@gmail.com).
} 


\section{Introducción}

En la mayoría de los países de América Latina y el Caribe ha ocurrido un cambio estructural en el medio rural caracterizado por el tránsito de una economía dominada por las actividades agropecuarias a una economía más diversificada (CEPAL; FAO; IICA, 2014; KAY, 2009). Lo anterior se ve reflejado en el mercado de trabajo a través de una reducción en la importancia del empleo agropecuario, sobre todo del empleo por cuenta propia sin remuneración, respecto al incremento del empleo no agropecuario, en especial el asalariado (MARTÍNEZ-DOMÍNGUEZ, 2015; GARAY, 2014). En este estudio se considera empleo no agropecuario, ya sea por cuenta propia o asalariado, al empleo de miembros del hogar en los sectores de industria, comercio y servicios (MARTínEZ-DOMÍNGUEZ, 2015). Datos de encuestas a hogares para diez países de América Latina muestran que el empleo no agropecuario ha aumentado en términos absolutos y a una tasa de crecimiento mayor que el empleo agropecuario (CEPAL; OIT; FAO, 2012). Asimismo, desde el punto de vista de la generación de ingresos, el empleo no agropecuario ha incrementado su participación en el ingreso total de los hogares rurales (CEPAL; OIT; FAO, 2012; YÚNEZ et al., 2015).

El sector agropecuario mexicano ha perdido importancia en la generación de empleo para la población rural. De acuerdo con información de la Encuesta Nacional de Ocupación y Empleo (ENOE), en el período 2006-2014 la población ocupada en el sector primario, conformado por las actividades de agricultura, ganadería, silvicultura, pesca y minería, disminuyó anualmente $0,91 \%$, en tanto que el empleo en actividades no agropecuarias creció 2,43\% (INEGI, 2006, 2014a). Lo anterior se refleja en la composición del ingreso rural: datos de la Encuesta Nacional de Ingresos y Gastos de los Hogares (INEGI, 2014b) muestran que las actividades relacionadas con el sector no agropecuario contribuyeron con el $73,9 \%$ del ingreso total de los hogares rurales.

México ha experimentado un proceso de desagrarización caracterizado por la disminución gradual de la contribución de las actividades agropecuarias al ingreso de las familias, el incremento en la migración y el envejecimiento de la población en el sector rural (ESCALANTE et al., 2007). Esto ha provocado que los hogares adopten múltiples estrategias de sobrevivencia, incluidas las actividades agropecuarias y no agropecuarias (GÓMEZ, 2013; GARAY, 2014). Los estudios de Yúnez et al. (2015) y de De Janvry y Sadoulet (2001) señalan que las actividades no agropecuarias generan más de la mitad de los ingresos en los hogares rurales mexicanos. Asimismo, a partir de la década del setenta aumentó la participación de la mujer en todos los ámbitos y en especial en la actividad económica, al pasar del 19\% en 1970 al 37\% en 1997 (GARCíA, 2001). El cambio en la fuerza de trabajo puede estar influenciado por diversos factores, como las reformas económicas, la creciente importancia del sector no agropecuario, el aumento de la escolaridad femenina y el descenso de la fecundidad (PEDRERO, 2003). Dado el papel visible y cada vez más importante que ha adquirido la mujer como agente generador de ingresos y de sustento familiar, es relevante estudiar la participación de las mujeres en el sector rural y entender los factores 
que incentivan su incorporación en actividades no agropecuarias asalariadas y por cuenta propia (RODRÍGUEZ; MUÑOZ, 2015; FAWAZ; SOTO, 2012).

El objetivo de esta investigación consiste en identificar los factores que determinan la participación por sexo en actividades no agropecuarias del México rural. Se pretende responder a la pregunta «¿Cuáles son las características de los individuos (hombres y mujeres), del hogar y del contexto local que influyen en la decisión de participar en el sector no agropecuario?». Al identificar los factores que contribuyen a la respuesta de esta pregunta es posible señalar que los elementos que distinguen al presente estudio de las investigaciones previas, así como las aportaciones al análisis del tema, son los siguientes: 1) la distinción de los determinantes por sexo, que reflejan la heterogeneidad entre hombres y mujeres al tomar las decisiones de participación en actividades no agropecuarias; 2) el uso de datos panel, que disminuyen los problemas econométricos que afectan a las estimaciones con datos de corte transversal utilizados en trabajos anteriores; y 3) no solo confirmar la importancia de las actividades no agropecuarias en el sector rural de México, sino, además, resaltar los efectos diferenciadores de participación al considerar una posición distintiva entre hombres y mujeres, lo cual contribuye a continuar y profundizar en investigaciones desde dicha óptica.

De esta manera, las hipótesis de trabajo planteadas en el estudio son las siguientes: 1) dado que los salarios y rendimientos en el sector agropecuario son estacionales y bajos, se espera que hombres y mujeres con mayores niveles de escolaridad tengan una mayor probabilidad de abandonar el sector agropecuario e incorporarse al sector no agropecuario asalariado; 2) el hecho de pertenecer a alguno de los grupos indígenas reduce la probabilidad de participar en actividades no agropecuarias asalariadas; y 3) la composición por género de la fuerza de trabajo al interior del hogar afecta la decisión de transitar hacia el sector no agropecuario: se espera que en hogares con mayor número de mujeres en edad de trabajar, ellas incursionen en actividades no agropecuarias.

El resto del documento se organiza de la siguiente manera. La sección dos aborda el sustento conceptual de género y discute la literatura sobre las estrategias de diversificación. En la sección tres se presenta una descripción de la base de datos y en la cuatro, la metodología. Las estadísticas descriptivas y los resultados se discuten en la sección cinco. En la última sección se exponen las conclusiones y las reflexiones finales.

\section{Revisión conceptual y literatura}

En Europa, Ploeg y Roep (2003) señalan que el desarrollo rural aparece en la agenda europea en respuesta a la crisis del paradigma de la modernización agrícola y a través de este desarrollo rural se diversifican las fuentes de ingreso, con el fin de aumentar el ingreso total. En Latinoamérica, las sociedades y economías rurales han presentado cambios estructurales motivados por la globalización (KAY, 2009). Estos cambios dieron origen al surgimiento del enfoque de la nueva ruralidad, el cual plantea que el medio rural es un 
conjunto de regiones cuya población desarrolla diversas actividades que interactúan entre sí y, al mismo tiempo, observa una interdependencia del mundo rural con el resto de la economía y el medio urbano (OSORIO, 2011).

Dentro de las transformaciones de la nueva ruralidad en América Latina se encuentran el desarrollo de actividades fuera de la unidad productiva; la interacción de los ámbitos rural y urbano; la migración y las remesas, y la flexibilización y feminización del trabajo rural (KAY, 2009). Esto último motiva a considerar en la discusión el tema de género, que está presente en las transformaciones sociales y económicas del sector rural a través de las creencias, actitudes, comportamientos y acciones socialmente construidas que diferencian a los hombres de las mujeres y que establece patrones de expectativas para los individuos y ordena procesos sociales de la vida cotidiana (ESPINO, 2010; JUÁREZ, 2013; SOSA; ROMÁN, 2015). Desde esta perspectiva, es importante analizar las desigualdades entre mujeres y hombres del ámbito rural que participan en el sector no agropecuario.

La incorporación del género en el análisis económico da cuenta de la división sexual de trabajo, que responde a cuestiones económicas, sociales y culturales y muestra una diferenciación histórica en el reparto de funciones y espacios para llevarlas a cabo: las mujeres en el ámbito privado, sin remuneración ni prestaciones, en actividades como el cuidado, el trabajo doméstico y los quehaceres del hogar, y los hombres en el ámbito público, con remuneración económica y en ciertos contextos con prestaciones (INMUJERES, 2015).

Las tendencias asociadas con las crisis económicas, las políticas de liberalización y la globalización incluyen la diversificación de las estrategias de generación de ingresos de los hogares rurales y la progresiva participación de las mujeres como trabajadoras en los sectores agropecuario y no agropecuario (VALDÉS, 2012; DEERE, 2006; BENARÍA, 1991). Los procesos de cambios productivos y sociales inducidos por la modernización y la globalización han hecho necesario el trabajo remunerado de nuevos miembros de la familia, lo cual obedece a proyectos personales, a estrategias económicas familiares, a nuevas expectativas que instala la modernidad, a necesidades de reproducción económica de la familia, a la aspiración a identidad propia o a la autonomía e independencia económica (FAWAZ; SOTO, 2012; ORTEGA, 2012).

La capacidad de las mujeres para generar ingresos a través de sus actividades productivas contribuye al bienestar familiar. Sin embargo, ello depende en mayor medida de la igualdad de género en el acceso a recursos y oportunidades para participar en el mercado de trabajo (KABEER, 2016; FIDA, 2012).

El trabajo se concibe como el medio que permite a las personas desarrollarse y extender otras capacidades. Desde la perspectiva de género, el trabajo y su división social tienen relación con la autonomía, el empoderamiento económico y la libertad de elección (INMUJERES, 2015). La autonomía se refiere a la participación de las mujeres en el mercado de trabajo y a su contribución económica al hogar, que aumenta su poder de decisión (RODRÍGUEZ; MUÑOZ, 2015; FAWAZ; RODRÍGUEZ, 2013; ROJAS, 2010). El empoderamiento económico se asocia con el acceso a educación, empleo, activos y crédito (KABEER, 2016). 
Por último, la libertad de elección se relaciona con la participación de la mujer en el ámbito educativo, laboral y político (INMUJERES, 2015).

En al ámbito cultural, el modelo patriarcal de familia presenta rasgos predominantes de autoridad y poder centralizados en el hombre proveedor y la cónyuge mujer subordinada y relegada a la esfera doméstica, dedicada a las tareas de reproducción y cuidado de los hijos (ORTEGA, 2012; ROJAS, 2010; CASIQUE, 2008). Existe evidencia de que las mujeres consideran al empleo como una cuestión secundaria que realizan como complemento de sus actividades en el hogar o en caso de problemas económicos en la familia; ellas se identifican básicamente con sus funciones de reproducción en el hogar (SOSA; ROMÁN, 2015; ABRAMO, 2004).

En México, como en otros países de América Latina, el acceso de las mujeres al trabajo fuera del hogar se da en condiciones de segregación ocupacional-actividades económicas y ocupaciones que concentran a hombres y mujeres por separado-, discriminación salarial -relacionada con ingresos diferenciados por género con las mismas capacidades- y precariedad laboral -vinculada a empleos asalariados, temporales y sin prestaciones laborales- (ESPINO, 2010; COOPER, 2009; DE OLIVEIRA; ARIZA, 2000).

Con base en la información del primer trimestre de 2015 de la ENOE (INEGI, 2015), se indica que para el ámbito rural mexicano $71,1 \%$ de la población ocupada son hombres y el resto mujeres. En el período 2006-2014 los hombres incrementaron su participación en el sector primario en 1,19\% promedio anual, mientras que en el caso de las mujeres hubo una reducción de alrededor de 1,29\% en promedio cada año. Cabe resaltar el crecimiento que tuvieron los sectores secundario y terciario para ambos géneros $(2,19 \%$ hombres y $2,72 \%$ mujeres), aunque las mujeres presentan el mayor aumento en el período (INEGI, 2006, 2014a). Sin duda, esto muestra los cambios ocurridos y la relevancia del sector no agropecuario como fuente de empleo para hombres y mujeres en el medio rural mexicano. En respaldo a las cifras anteriores, Garay (2014), Sosa y Román (2015) señalan que las mujeres del México rural han aumentado su participación en actividades no agropecuarias, donde el sector comercio y servicios ha absorbido gran parte de la mano de obra femenina.

Aunque las mujeres en el sector rural desempeñan un papel esencial en el desarrollo, lo cierto es que ellas enfrentan una serie de obstáculos estructurales e institucionales (TANWIR; SAFDAR, 2013). Primero, en la mayoría de los países en desarrollo, las mujeres de las zonas rurales tienen poco o nulo acceso a activos como la tierra agrícola (DEERE; LEÓN, 2003; FLATØ; MUTTARAK; PELSER, 2017). En Latinoamérica, un muy bajo porcentaje de mujeres son dueñas de tierra y la desigualdad de género en la propiedad esta se relaciona con la preferencia masculina en la herencia, la compra y la dotación o repartición del Estado (DEERE; LEÓN, 2003). Segundo, la desigualdad de género persiste en la propiedad de ganado, donde los hombres son dueños del ganado mayor como bovinos y equinos, en tanto las mujeres son propietarias de ganado menor como cabras u ovejas, y aves de corral (ARRIAGA et al., 2005; NJUKI; SANGINGA, 2013). Tercero, tienen un limitado acceso al mercado formal de crédito, lo cual se relaciona con la falta del título de propiedad (KLASEN; 
LECHTENFELD; POVEL, 2015; FLATØ; MUTTARAK; PELSER, 2017). Cuarto, presentan menores niveles de escolaridad en comparación con los hombres (KLASEN; LAMANNA, 2009; TANWIR; SAFDAR, 2013). Al respecto, Klasen y Lamanna (2009) señalan que promover la educación de las mujeres reduce los niveles de fertilidad, de mortalidad infantil y promueve la educación de la próxima generación. Quinto, tienen menos acceso al mercado de trabajo y menores salarios que los hombres cuando trabajan (OOSTENDORP, 2009; KLASEN; LECHTENFELD; POVEL, 2015). Sexto, tienen acceso limitado a las tecnologías de la información y comunicación (FLATØ; MUTTARAK; PELSER, 2017). Séptimo, las normas socioculturales restringen su movilidad, su interacción con miembros del otro sexo y el tipo de actividades que pueden desarrollar (RODRÍGUEZ; MUÑOZ, 2015).

Sumados a estas desventajas que enfrentan las mujeres, existen desafíos particulares que ellas afrontan en su papel de jefas del hogar, como la doble carga de trabajo al dedicarse a las actividades agropecuarias, al cuidado del hogar y al cuidado de niños y adultos mayores (CASIQUE, 2008; ROJAS, 2010; SOSA; ROMÁN, 2015). Además, en muchos casos, las jefas de hogar carecen del apoyo de redes sociales o del Estado (KLASEN; LECHTENFELD; POVEL, 2015).

Investigaciones realizadas en distintos contextos sugieren que el acceso de las mujeres a recursos como educación, empleo, tierra, transferencias monetarias y crédito se asocia con un mayor bienestar familiar, incluyendo la salud de los niños y su educación (KABEER, 2016; KLASEN; LAMANNA, 2009).

Asimismo, estudios previos sobre la diversificación del ingreso han puesto en evidencia que los hogares rurales no dependen exclusivamente del sector agropecuario (ELLIS, 1998; LANJOUW; LANJOUW, 2001; ZHAO; BARRY, 2014), sino que las actividades no agropecuarias contribuyen de manera significativa en el ingreso total y, en ocasiones, representan el único sustento para los hogares que no poseen tierra agrícola (REARDON; BERDEGUÉ; ESCOBAL, 2001).

Las decisiones del hogar respecto a la oferta laboral en el sector no agropecuario se conceptualizan como un problema de optimización con restricciones, donde el conjunto de incentivos señala el rendimiento relativo de las actividades agropecuarias y no agropecuarias, así como la propiedad y el acceso a los recursos determinan la capacidad para participar en estas actividades (REARDON et al., 2007).

Adicionalmente, Barrett, Reardon y Webb (2001) señalan que los incentivos para diversificarse en actividades no agropecuarias se dividen en dos: los factores pull y los push. Los factores pull incluyen mayores ganancias o menor riesgo en las actividades no agropecuarias versus las agropecuarias. Además, el alto rendimiento en el sector no agropecuario permite la acumulación de capital, que puede reinvertirse en tecnología agropecuaria. Los factores push comprenden las restricciones asociadas al factor tierra, al mayor riesgo en el sector agropecuario provocado por eventos climáticos extremos, como sequías e inundaciones y las fallas en los mercados de seguros, crédito e insumos. Este 
conjunto de factores, pull y push, se considera en los distintos niveles de agrupación de las variables utilizadas en el presente trabajo.

Reardon et al. (2007) y Wiggins y Hazell (2011) señalan que las variables de capacidad que permiten a los hogares diversificarse en actividades no agropecuarias abarcan los capitales humano, social, financiero, físico y organizacional, los cuales pueden incluir bienes públicos y privados a escala regional o ser comunes a un grupo de hogares. Por ejemplo, contar con infraestructura en buenas condiciones reduce los costos de transporte para quienes se dedican a las actividades no agropecuarias. Barrett, Reardon y Webb (2001) indican, por un lado, que, desde la perspectiva push, la diversificación es impulsada por la capacidad de asumir riesgos limitados en presencia de sistemas financieros débiles e incompletos que crean fuertes incentivos para seleccionar un portafolio de actividades con el fin de estabilizar el ingreso y el consumo por las restricciones en el trabajo y los mercados de tierra, y, por otro lado, desde la perspectiva pull, los motores locales de crecimiento, como la agricultura comercial o la proximidad a las áreas urbanas, generan las oportunidades para diversificar el ingreso. En el caso del sector rural de México, MartínezDomínguez (2015) y Yúnez et al. (2015) muestran que los hogares participan en actividades no agropecuarias asalariadas por ambos tipos de factores.

Por último, el contexto local está relacionado con la ubicación geográfica, las condiciones económicas de la economía local y la infraestructura, las cuales son cruciales para la participación en el sector no agropecuario (DIRVEN, 2011; JONASSON; HELFAND, 2010).

\section{Fuentes de información}

El estudio utiliza datos tipo panel de la Encuesta Nacional a Hogares Rurales de México (ENHRUM) I y II. Las encuestas se obtuvieron durante los primeros trimestres de 2003 y 2008 y proporcionan información de 2002 y 2007, respectivamente. El panel consta de 1.543 hogares ubicados en 80 localidades distribuidas en 14 estados, estos últimos agrupados en cinco regiones: sur-sureste, centro, centro-occidente, noroeste, noreste (Figura 1). El INEGI diseñó la muestra de la ENHRUM para proporcionar una caracterización estadísticamente confiable de la población que vive en localidades rurales de entre 500 y 2.499 habitantes. Se utilizaron datos de la ENHRUM en el período mencionado debido a que no existe en México otra encuesta que recabe información tipo panel para estudiar el comportamiento de los hogares del sector rural mexicano.

La ENHRUM contiene información demográfica y económica de los hogares y sus miembros. En particular, proporciona información detallada sobre la participación laboral en los sectores agropecuario y no agropecuario y por tipo de trabajo: asalariado y por cuenta propia. El cuestionario incluyó un apartado de trabajo fuera del campo, en el que se registró información relacionada con la prestación de servicios privados y gubernamentales, construcción, industria, educación y comercio local y regional por parte de los miembros del hogar con 12 años y más. En dichas actividades los miembros del hogar se emplearon 
por un salario. Además, se dispone de datos sobre el tiempo que los individuos dedicaron al trabajo por cuenta propia en las diferentes actividades económicas del hogar: agricultura, ganadería y recolección de recursos naturales, así como negocios propios de manufactura, servicios y comercio al por menor. En este estudio se considera la participación laboral en actividades no agropecuarias asalariadas o por cuenta propia de los individuos entre 12 y 65 años, cualquiera haya sido el tiempo que dedicaron a dichas actividades durante los años de referencia.

FIGURA 1

Regiones y distribución geográfica de localidades encuestadas en la ENHRUM

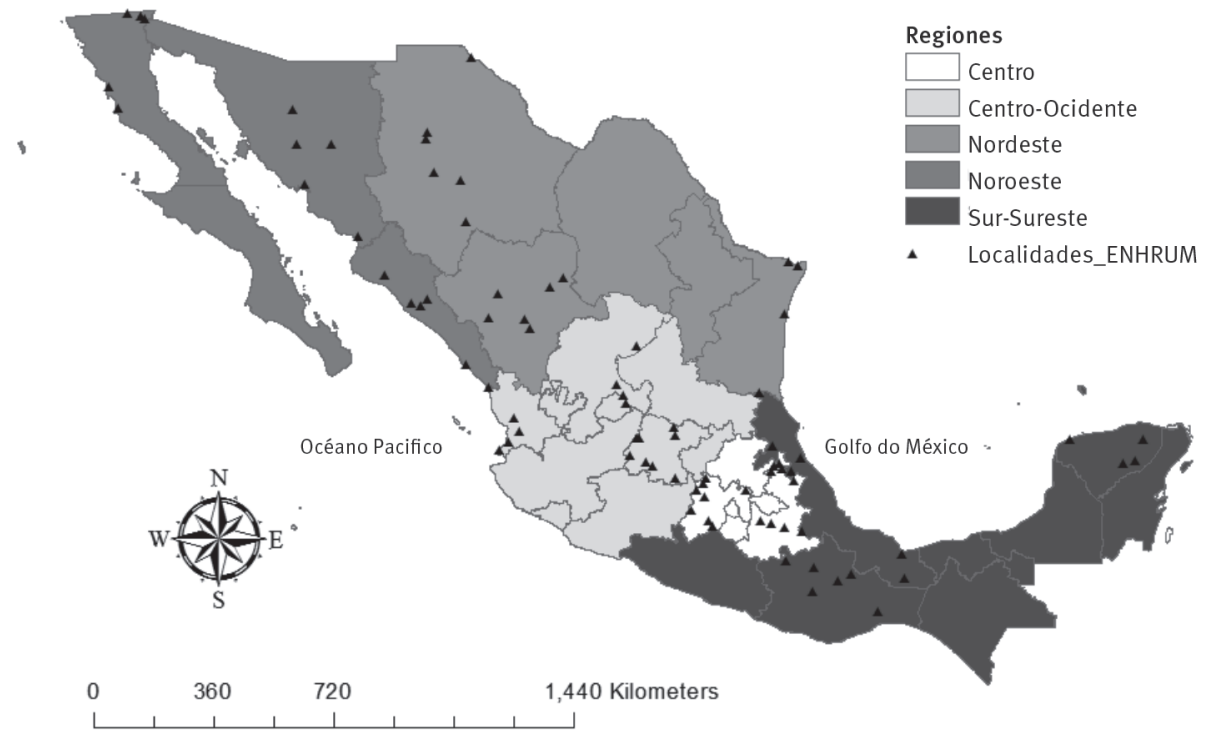

Fuente: Tomado de Desarrollo y Alimentación Sustentable, A.C.

\section{Modelo empírico y método de estimación}

Para examinar los factores que influyen en la participación por sexo en el sector no agropecuario asalariado y por cuenta propia, las funciones de participación para cada individuo, $i$, del sexo, $g$, se expresan en la siguiente ecuación: ${ }^{1}$

$T_{i g}=\beta_{0}+\beta_{1} I_{i g}+\beta_{2} H_{i g}+\beta_{3} L_{i g}+\varepsilon_{i g}$

La variable dicotómica de respuesta $T_{i g}$ indica la participación en actividades no agropecuarias. Las variables independientes están representadas por los vectores $I_{i g}, H_{i g}$ y $L_{i g}$. Los $\beta_{S}$ son los coeficientes a estimar; $\varepsilon_{i g}$ representa variables no observadas que influyen

\footnotetext{
${ }^{1}$ Este tipo de modelación se ha empleado en la literatura de forma regular para analizar los determinantes y efectos diferenciados entre grupos de individuos, países y sectores económicos. Véase, por ejemplo: (SU et al., 2016; GREENSTEIN, 2000; AMUEDO-DORANTES; DE LA RICA, 2011; CHRISTOFIDES; POLYCARPOU; VRACHIMIS, 2013; VALENZUELA; DURYEA, 2011; CASIQUE, 2011).
} 
en la ecuación de oferta de trabajo. El vector $I_{i g}$ contiene un grupo de variables relacionadas con características individuales como experiencia, grupo étnico, estado civil y nivel de escolaridad. La experiencia en el mercado de trabajo se calculó como se hace habitualmente en la literatura sobre rendimientos de la escolaridad (MINCER, 1974): la edad del individuo menos el número de años de escolaridad, menos seis; esto es, el número de años antes de iniciar la etapa escolar. Se incluyó el término lineal y cuadrático de la experiencia laboral para capturar los posibles efectos no lineales de esta variable sobre la participación en el sector no agropecuario. En grupo étnico, 1 indica que el individuo es hablante de lengua indígena y 0 el caso contrario. En estado civil, 1 indica que el individuo es casado y 0 el caso contrario. Se establecieron cinco niveles de escolaridad: sin educación representa la categoría de referencia; Primaria1, de 1 a 3 años de escolaridad; Primaria2, de 4 a 6 años de escolaridad; Secundaria, de 7 a 9 años de escolaridad; Bachillerato, de 10 a 12 años de escolaridad, y Licenciatura, más de 12 años de escolaridad.

El vector $H_{i g}$ representa un grupo de variables a nivel hogar, como el número de migrantes en México y Estados Unidos, la disponibilidad de activos físicos agropecuarios, tierra agrícola y ganado y el acceso a crédito. Se agregó el número de dependientes en el hogar, es decir, el número de niños menores de 6 años y el número de personas mayores de 65 años, ya que ambas variables influyen en la participación de las mujeres en el empleo no agropecuario (RODRÍGUEZ; MUÑOZ, 2015; GARAY, 2014). Se añadió el acceso de los hogares a los programas gubernamentales de transferencias más importantes en cuanto a cobertura y presupuesto destinado al sector rural: Procampo y Oportunidades. En conjunto, ambos programas ocupan cerca de la tercera parte del presupuesto federal mexicano destinado a intervenciones para el desarrollo social (CONEVAL, 2008). Los dos programas brindan apoyos monetarios a la población: Procampo opera desde 1993 y otorga apoyos con el propósito de mejorar la economía de los productores a través de sus cultivos y Oportunidades, hoy Prospera, opera desde 1997 y tiene como objetivo reducir la transmisión intergeneracional de la pobreza por medio de la educación, la salud y la nutrición (CONEVAL, 2008).

Se incorporó también un índice de riqueza con la intención de reflejar la situación económica del hogar en el largo plazo. El índice se construyó mediante análisis de componentes principales con información de activos y características de la vivienda (FILMER; PRITCHETT, 2001).

El vector $L_{i g}$ denota un conjunto de características de contexto local: el tiempo en transporte público medido en minutos a la localidad urbana más cercana, el número de servicios financieros, de comunicación y transporte. Además, se incluyó un grupo de variables dicotómicas con el propósito de capturar las diferencias entre las regiones geográficas incluidas en el estudio (Figura 1). Este tipo de variables ha sido considerado como elemento central en los procesos de desarrollo e incremento de bienestar que experimentan los hogares rurales (JONASSON; HELFAND, 2010; ELLIS, 1998).

Para modelar la participación por sexo en las actividades no agropecuarias asalariadas y por cuenta propia se estimaron regresiones logísticas de efectos aleatorios. Se obtuvieron 
errores estándar robustos a la heterocedasticidad mediante el método bootstrap con 400 réplicas (CAMERON; TRIVEDI, 2009).

\section{Estadísticas descriptivas y resultados}

Como se dijo, el análisis incluyó a los individuos entre 12 y 65 años de edad que trabajaron en ambos años de la ENHRUM: 2002 y 2007. Se determinó la ocupación principal con base en el mayor número de horas dedicadas en las diferentes actividades. Las ocupaciones se dividieron en cuenta propia y asalariadas y en ambos casos se incluyeron tanto actividades agropecuarias como no agropecuarias. A continuación se presentan los resultados del ejercicio econométrico y las principales características por género de la participación en los sectores incluidos en el análisis.

\section{La participación por sexo en los sectores económicos}

Al dividir a la fuerza de trabajo rural entre hombres y mujeres, se obtiene que el $66 \%$ son hombres y el resto mujeres. Ellas se dedican en mayor medida a las actividades por cuenta propia, mientras que los hombres, a las asalariadas. Las principales ocupaciones de las mujeres se encuentran en la ganadería y en actividades no agropecuarias asalariadas (Tabla 1), en tanto que los hombres están más involucrados en actividades asalariadas agropecuarias y no agropecuarias y en las agrícolas por cuenta propia. Los resultados de la prueba estadística de comparación de proporciones señalan que las mujeres aumentaron su participación en la recolección de recursos naturales y en el sector agropecuario asalariado, mientras que esta disminuyó en la actividad ganadera. Los hombres redujeron su intervención en la agricultura y la aumentaron en el aprovechamiento de recursos naturales (Tablas 1 y 2 ).

TABLA 1

Proporción de la fuerza de trabajo femenina por sector de ocupación - 2002-2007

\begin{tabular}{|c|c|c|c|c|c|c|}
\hline \multirow{2}{*}{$\begin{array}{l}\text { Tipo de } \\
\text { empleo }\end{array}$} & \multirow{2}{*}{ Sector } & \multicolumn{5}{|c|}{ Mujeres } \\
\hline & & Media & $\begin{array}{c}\text { Desviación } \\
\text { estándar }\end{array}$ & Media & $\begin{array}{l}\text { Desviación } \\
\text { estándar }\end{array}$ & $\begin{array}{c}\text { Diferencia } \\
\text { de medias } \\
\text { p-valor }\end{array}$ \\
\hline \multirow{5}{*}{ Cuenta propia } & \multicolumn{6}{|c|}{ Agropecuario } \\
\hline & Agricultura & 0,13 & 0,34 & 0,14 & 0,35 & 0,58 \\
\hline & Recursos naturales & 0,08 & 0,27 & 0,14 & 0,35 & $0 \star \star \star \star$ \\
\hline & \multicolumn{6}{|c|}{ No agropecuario } \\
\hline & Bienes y servicios & 0,16 & 0,36 & 0,15 & 0,36 & 0,71 \\
\hline
\end{tabular}

Fuente: Elaboración propia con datos de la ENHRUM I y II.

Nota: ${ }^{\star \star \star}$ significativo a $1 \%,{ }^{\star \star}$ significativo a $5 \%,{ }^{*}$ significativo a $10 \%$. 
TABLA 2

Proporción de la fuerza de trabajo masculina por sector de ocupación - 2002-2007

\begin{tabular}{|c|c|c|c|c|c|c|}
\hline \multirow{3}{*}{$\begin{array}{l}\text { Tipo de } \\
\text { empleo }\end{array}$} & \multirow{3}{*}{ Sector } & \multicolumn{5}{|c|}{ Hombres } \\
\hline & & \multicolumn{2}{|c|}{2002} & \multicolumn{2}{|c|}{2007} & \multirow{2}{*}{$\begin{array}{c}\text { Diferencia } \\
\text { de medias } \\
\text { p-valor }\end{array}$} \\
\hline & & Media & $\begin{array}{l}\text { Desviación } \\
\text { estándar }\end{array}$ & Media & $\begin{array}{l}\text { Desviación } \\
\text { estándar }\end{array}$ & \\
\hline \multirow{6}{*}{$\begin{array}{l}\text { Cuenta } \\
\text { propia }\end{array}$} & \multicolumn{6}{|c|}{ Agropecuario } \\
\hline & Agricultura & 0,20 & 0,40 & 0,15 & 0,36 & $0 * \star \star$ \\
\hline & Ganadería & 0,12 & 0,32 & 0,14 & 0,34 & 0,12 \\
\hline & Recursos naturales & 0,07 & 0,25 & 0,09 & 0,28 & $0,05^{\star}$ \\
\hline & \multicolumn{6}{|c|}{ No agropecuario } \\
\hline & Bienes y servicios & 0,06 & 0,23 & 0,07 & 0,26 & 0,10 \\
\hline \multirow{2}{*}{ Asalariado } & Agropecuario & 0,26 & 0,44 & 0,27 & 0,44 & 0,57 \\
\hline & No agropecuario & 0,30 & 0,46 & 0,28 & 0,45 & 0,31 \\
\hline \multicolumn{2}{|c|}{ Total de individuos de la muestra } & 1328 & & & & \\
\hline
\end{tabular}

Fuente: Elaboración propia con datos de la ENHRUM I y II.

Nota: ${ }^{\star \star \star}$ significativo a $1 \%,{ }^{\star \star}$ significativo a $5 \%,{ }^{\star}$ significativo a $10 \%$.

La Tabla 3 proporciona estadísticas adicionales de la muestra conjunta para ambos años de la encuesta. Los datos indican que los hombres participan en mayor medida que las mujeres en las actividades asalariadas no agropecuarias (28\% y $22 \%$ respectivamente). Lo contrario ocurre en las actividades por cuenta propia no agropecuarias, en las que las mujeres se emplean más que los hombres (13\% y $8 \%$ respectivamente). Con respecto a las transferencias gubernamentales, las mujeres reciben en mayor proporción recursos del programa Oportunidades, mientras que lo opuesto sucede con el programa Procampo. Por último, las características de la localidad muestran que el tiempo promedio en transporte público a la localidad urbana más cercana es de 42 minutos para las mujeres y de 43 minutos para los hombres. No hay diferencias evidentes entre los distintos niveles de escolaridad y hablar una lengua indígena. En cambio, los hombres tienen mayor dotación de capital y las mujeres registran mayor migración a otras partes de México y cuentan con mayor número de personas dependientes (niños menores de seis años y adultos mayores de 65 años).

TABLA 3

Estadísticas descriptivas - 2002-2007

\begin{tabular}{lcc}
\hline \multicolumn{1}{c}{ Variables } & $\begin{array}{c}\text { Mujeres } \\
\text { (media) }\end{array}$ & $\begin{array}{c}\text { Hombres } \\
\text { (media) }\end{array}$ \\
\hline Participación en actividades no agropecuarias asalariadas & 0,22 & 0,28 \\
Participación en actividades no agropecuarias por cuenta propia & 0,13 & 0,08 \\
Experiencia & 22,37 & 22,92 \\
Hablante de lengua indígena & 0,18 & 0,20 \\
Estado civil & 0,51 & 0,55 \\
Primaria 1 (1-3 años) & 0,17 & 0,18 \\
Primaria 2 (4-6 años) & 0,35 & 0,34 \\
Secundaria (7-9 años) & 0,25 & 0,27 \\
Bachillerato (10-12 años) & 0,11 & 0,10 \\
\hline
\end{tabular}


(Continuación)

\begin{tabular}{lcc}
\hline \multicolumn{1}{c}{ Variables } & $\begin{array}{c}\text { Mujeres } \\
\text { (media) }\end{array}$ & $\begin{array}{c}\text { Hombres } \\
\text { (media) }\end{array}$ \\
\hline Licenciatura (> 12 años) & 0,04 & 0,04 \\
Promedio de educación del hogar & 6,57 & 6,43 \\
Número de mujeres $\geq 12$ años & 2,54 & 2,09 \\
Número de niños <6 años & 0,61 & 0,56 \\
Número de adultos > 65 años & 0,24 & 0,20 \\
Número de migrantes en México & 0,64 & 0,57 \\
Número de migrantes en Estados Unidos & 0,45 & 0,45 \\
Disponibilidad de tierra agrícola & 0,46 & 0,49 \\
Propiedad de ganado & 0,40 & 0,42 \\
Disponibilidad de crédito formal & 0,23 & 0,22 \\
Transferencias del gobierno (Procampo) & 0,40 & 0,43 \\
Transferencias del gobierno (Oportunidades) & 0,61 & 0,57 \\
Tiempo (minutos a la localidad urbana más cercana) & 41,71 & 42,93 \\
Número de servicios en la localidad & 4,12 & 3,94 \\
R1 Sur-Sureste & 0,19 & 0,22 \\
R2 Centro & 0,31 & 0,25 \\
R3 Centro-occidente & 0,21 & 0,21 \\
R4 Noroeste & 0,21 & 0,20 \\
R5 Noreste & 0,08 & 0,12 \\
Tamaño de muestra & 2662 & 3614 \\
\hline
\end{tabular}

Fuente: Elaboración propia con datos de la ENHRUM I y II.

\section{Participación por sexo en el sector no agropecuario asalariado}

La Tabla 4 contiene los resultados de los modelos logísticos de datos panel, donde se incluyen los parámetros estimados, el estadístico z y los efectos marginales evaluados en los valores promedio de las variables explicativas. ${ }^{2}$ Los resultados de las regresiones indican que las variables de capital humano, la disponibilidad de activos físicos agropecuarios, las redes migratorias en Estados Unidos, las transferencias gubernamentales y el acceso a infraestructura determinan la participación de los habitantes en el sector rural mexicano.

La evidencia empírica demuestra que las características individuales inciden en la participación en el sector no agropecuario asalariado. La experiencia es positiva y significativa para hombres y mujeres, aunque a tasas decrecientes, lo que implica que los trabajadores de mayor edad sean considerados en menor medida para el mercado laboral y que su posibilidad de participación disminuya. Hablar una lengua indígena reduce la probabilidad de ocuparse en esta fuente de empleo para hombres y mujeres, resultado que confirma la segunda hipótesis y es consistente con otros estudios (YÚNEZ et al., 2015; DE JANVRY; SADOULET, 2001). Por su parte, el estado civil influye en la participación solo de las mujeres, ya que estar casadas disminuye la probabilidad de incorporarse al mercado

\footnotetext{
$\overline{2}$ Por sugerencia de uno de los revisores, en las Tablas 4 y 5 se incorporan los intervalos de confianza al $95 \%$ para cada coeficiente de las regresiones efectuadas.
} 
de trabajo. Con respecto a lo último, Garay (2014) señala que las mujeres casadas asumen mayores responsabilidades domésticas, lo que limita el trabajo fuera del hogar.

En las variables de educación es posible observar, tanto para hombres como para mujeres, que su impacto en la probabilidad de dedicarse a actividades no agropecuarias asalariadas es positivo y se incrementa conforme se accede a niveles de escolaridad mayores. Lo anterior confirma la hipótesis de la importancia de la educación como un factor determinante para el mercado de trabajo no agropecuario. No obstante, solo el nivel de licenciatura es estadísticamente significativo para las mujeres, mientras que el efecto para los hombres comienza a identificarse a partir de la secundaria. Estos hallazgos reflejan un impacto diferenciador de la educación entre hombres y mujeres e indican que el mercado laboral no agropecuario presenta mayores requerimientos educativos para las mujeres que para los hombres. Las mujeres tienen mayor probabilidad de trabajar fuera del hogar cuando cuentan con educación superior, lo cual confirma el valor de una alta escolaridad para las mujeres encontrado en otros estudios (DOMÍNGUEZ; BROWN, 2013). Lo anterior sugiere que mientras los hombres consideran otros aspectos en la decisión de participar en las actividades no agropecuarias asalariadas, en el caso de las mujeres contar con educación profesional es una variable esencial para incorporarse en este tipo de ocupaciones.

Con respecto a las características del hogar, un mayor número de mujeres en la familia con edades de 12 años y más aumenta la posibilidad de que los hombres se empleen en las actividades no agropecuarias asalariadas. La presencia de niños no tiene un efecto significativo sobre la decisión de las mujeres de participar en el sector no agropecuario asalariado. Para el caso de los hombres, el efecto es positivo y significativo, lo que refleja el papel de proveedores económicos que estos asumen en los hogares rurales mexicanos (YÚNEZ et al., 2015).

Contar con redes migratorias en Estados Unidos disminuye la probabilidad de ingresar al sector no agropecuario para ambos sexos: en el caso de los hombres en $4,96 \%$ y en las mujeres en 3,50\% (Tabla 4). Lo anterior sugiere que, en promedio, para los hogares rurales de México es más atractivo incorporar a algunos de sus miembros al mercado laboral estadounidense que a los mercados laborales no agropecuarios locales. Un resultado similar fue encontrado por Martínez-Domínguez (2015) para el caso de hogares mexicanos, pero sin distinguir efectos diferenciados por sexo. La posesión de activos físicos agropecuarios como tierra agrícola y ganado tienen un efecto negativo para ambos sexos, y es mayor el efecto en el caso de los hombres, lo cual se explica porque las actividades agropecuarias del hogar son altamente demandantes de mano de obra familiar (YÚNEZ et al., 2015).

Por otro lado, la variable índice de riqueza impacta positivamente en la participación de los hombres en actividades de este sector, justo como se muestra en el coeficiente positivo $(2,67)$ y la significancia asociada a esta variable (Tabla 4). Con respecto a las transferencias del gobierno, existen marcadas diferencias entre hombres y mujeres. Los coeficientes asociados a estas variables, y presentes en la Tabla 4, muestran que las transferencias de Oportunidades impactan negativamente la participación de las mujeres en este sector, 
mientras que las de Procampo lo hacen de forma similar para el caso de los hombres. El resultado es razonable y esperado, ya que en México las transferencias de Oportunidades las reciben directamente las madres de familia con el propósito de brindar apoyo a mejorar el bienestar de la familia. Por su parte, Procampo beneficia directamente a la agricultura, actividad en la que los hombres participan en mayor proporción (CONEVAL, 2008).

TABLA 4

Resultados del modelo logístico de datos panel: participación por sexo en el sector no agropecuario asalariado - 2002-2007

\begin{tabular}{|c|c|c|c|c|c|c|c|c|}
\hline \multirow{4}{*}{ Participación } & \multicolumn{8}{|c|}{ Empleo no agropecuario asalariado } \\
\hline & \multicolumn{4}{|c|}{ Mujeres } & \multicolumn{4}{|c|}{ Hombres } \\
\hline & \multirow{2}{*}{$\begin{array}{l}\text { Efecto } \\
\text { marginal }\end{array}$} & \multirow{2}{*}{$\begin{array}{l}\text { Valor } \\
\text { (z) }\end{array}$} & \multicolumn{2}{|c|}{$\begin{array}{c}\text { Intervalo de } \\
\text { confianza }\end{array}$} & \multirow{2}{*}{$\begin{array}{l}\text { Efecto } \\
\text { marginal }\end{array}$} & \multirow{2}{*}{$\begin{array}{l}\text { Valor } \\
(\mathrm{z})\end{array}$} & \multicolumn{2}{|c|}{$\begin{array}{c}\text { Intervalo de } \\
\text { confianza }\end{array}$} \\
\hline & & & $\begin{array}{l}\text { Límite } \\
\text { inferior }\end{array}$ & $\begin{array}{l}\text { Límite } \\
\text { superior }\end{array}$ & & & $\begin{array}{l}\text { Límite } \\
\text { inferior }\end{array}$ & $\begin{array}{l}\text { Límite } \\
\text { superior }\end{array}$ \\
\hline Experiencia & 0,56 & $3,38^{\star \star \star}$ & 0,233 & 0,878 & 1,09 & $4,84^{\star \star \star}$ & 0,651 & 1,537 \\
\hline Experiencia al cuadrado & $-0,01$ & $-4,44^{\star \star \star}$ & $-0,021$ & $-0,008$ & $-0,02$ & $-5,34^{\star \star \star}$ & $-0,030$ & $-0,014$ \\
\hline Lengua indígena & $-3,98$ & $-2,46^{\star \star}$ & $-7,138$ & $-0,812$ & $-5,11$ & $-2,23^{\star \star}$ & $-9,601$ & $-0,609$ \\
\hline Estado civil (casado(a)=1) & $-8,49$ & $-4,87^{\star \star \star}$ & $-11,909$ & $-5,069$ & 1,51 & 0,69 & $-2,786$ & 5,810 \\
\hline Primaria 1 (1-3 años) & $-5,20$ & $-2,39 * \star$ & $-9,448$ & $-0,944$ & 0,48 & 0,12 & $-7,506$ & 8,465 \\
\hline Primaria 2 (4-6 años) & $-3,16$ & $-1,05$ & $-9,044$ & 2,727 & 2,92 & 0,70 & $-5,310$ & 11,147 \\
\hline Secundaria (7-9 años) & $-1,19$ & $-0,35$ & $-7,811$ & 5,422 & 11,99 & $1,98^{\star \star}$ & 0,141 & 23,830 \\
\hline Bachillerato (10-12 años) & 4,08 & 0,74 & $-6,671$ & 14,841 & 16,71 & $1,95^{\star *}$ & $-0,068$ & 33,489 \\
\hline Licenciatura (> 12 años) & 25,31 & $1,95^{\star \star}$ & $-2,037$ & 52,661 & 50,36 & $4,33^{\star \star *}$ & 27,545 & 73,168 \\
\hline $\begin{array}{l}\text { Promedio de escolaridad } \\
\text { por hogar }\end{array}$ & 0,03 & 0,08 & $-0,673$ & 0,730 & $-0,39$ & $-0,78$ & $-1,376$ & 0,594 \\
\hline $\begin{array}{l}\text { Número de mujeres de } 12 \\
\text { años y más }\end{array}$ & 0,62 & 1,30 & $-0,316$ & 1,561 & 1,75 & $2,83^{\star \star \star *}$ & 0,535 & 2,955 \\
\hline Número de niños < 6 años & $-0,54$ & $-0,93$ & $-1,690$ & 0,605 & 2,20 & $2,56^{\star \star}$ & 0,513 & 3,878 \\
\hline Número de adultos > 65 años & $-0,22$ & $-0,22$ & $-2,171$ & 1,739 & $-3,54$ & $-2,24^{\star \star}$ & $-6,645$ & $-0,445$ \\
\hline Migrantes en México & 0,40 & 0,69 & $-0,733$ & 1,525 & 1,32 & 1,65 & $-0,248$ & 2,882 \\
\hline $\begin{array}{l}\text { Migrantes en Estados } \\
\text { Unidos }\end{array}$ & $-3,50$ & $-3,52^{\star \star \star}$ & $-5,457$ & $-1,551$ & $-4,96$ & $-4,63^{\star \star \star}$ & $-7,065$ & $-2,861$ \\
\hline Índice de riqueza & 0,75 & 1,70 & $-0,113$ & 1,612 & 2,67 & $4,83^{\star \star \star}$ & 1,588 & 3,760 \\
\hline Tierra agrícola & $-3,59$ & $-2,37^{\star \star}$ & $-6,571$ & $-0,619$ & $-7,34$ & $-3,36^{\star \star *}$ & $-11,628$ & $-3,059$ \\
\hline Propiedad de ganado & $-5,32$ & $-4,00 * \star \star$ & $-7,924$ & $-2,714$ & $-5,77$ & $-3,43^{\star \star \star}$ & $-9,074$ & $-2,474$ \\
\hline Crédito formal & $-1,93$ & $-1,52$ & $-4,420$ & 0,564 & 0,62 & 0,37 & $-2,700$ & 3,940 \\
\hline $\begin{array}{l}\text { Transferencias del gobierno } \\
\text { (Procampo) }\end{array}$ & $-2,01$ & $-1,50$ & $-4,622$ & 0,608 & $-12,40$ & $-6,82^{\star \star \star}$ & $-15,963$ & $-8,835$ \\
\hline $\begin{array}{l}\text { Transferencias del gobierno } \\
\text { (Oportunidades) }\end{array}$ & $-4,54$ & $-3,27^{\star \star \star}$ & $-7,257$ & $-1,817$ & 0,43 & 0,30 & $-2,442$ & 3,310 \\
\hline Tiempo (minutos) & $-0,03$ & $-2,08^{\star \star}$ & $-0,065$ & $-0,002$ & $-0,06$ & $-3,06^{\star \star \star}$ & $-0,102$ & $-0,022$ \\
\hline Servicios en la localidad & 0,12 & 0,90 & $-0,137$ & 0,368 & $-0,16$ & $-0,83$ & $-0,535$ & 0,216 \\
\hline R2 Centro & $-0,29$ & $-0,13$ & $-4,588$ & 4,018 & 3,20 & 1,02 & $-2,927$ & 9,329 \\
\hline R3 Centro-occidente & 8,72 & $2,21^{\star \star}$ & 0,980 & 16,462 & 9,43 & $2,23^{\star \star}$ & 1,152 & 17,717 \\
\hline R4 Noroeste & 0,49 & 0,19 & $-4,511$ & 5,486 & 4,35 & 1,17 & $-2,968$ & 11,676 \\
\hline R5 Noreste & $-0,51$ & $-0,18$ & $-6,144$ & 5,120 & 7,94 & 1,66 & $-1,453$ & 17,336 \\
\hline Wald Chi2 & 164,37 & & & & 277,51 & & & \\
\hline Log-likelihood ratio & $-1132,213$ & & & & $-1756,344$ & & & \\
\hline Tamaño de muestra & 2662 & & & & 3614 & & & \\
\hline
\end{tabular}

Fuente: Elaboración propia con datos de la ENHRUM I y II. Nota: ${ }^{\star * \star}$ significativos a $1 \%,{ }^{\star \star}$ significativos a $5 \%$. La región de referencia es la sur-sureste. 
Con respecto a las variables a nivel de localidad, el tiempo para llegar al centro urbano más cercano es negativo y significativo para mujeres y hombres, lo que advierte que entre más lejana se encuentre la localidad con posibles fuentes de empleo se reduce la posibilidad de desplazarse hacia ella. En el análisis por regiones, se considera la sur-sureste como la de referencia y los hombres participan en mayor medida en la centro-occidente, región con mayor dinamismo económico y oferta de empleos.

\section{Participación por sexo en el sector no agropecuario por cuenta propia}

En el sector no agropecuario por cuenta propia, los factores que influyen en la participación de hombres y mujeres están relacionados con la experiencia, el índice de riqueza y la disponibilidad de servicios en la localidad (Tabla 5). Las variables de educación no tienen incidencia en la decisión de hombres y mujeres de involucrarse en este tipo de actividades, lo que es consistente con investigaciones que señalan que los rendimientos económicos en estas ocupaciones son menores que los asociados al sector no agropecuario asalariado, que requiere mayores niveles educativos (YÚNEZ; TAYLOR, 2001).

En cuanto a las variables del hogar, un mayor número de mujeres con 12 años y más disminuye la probabilidad de que una mujer participe en actividades no agropecuarias por cuenta propia, lo que implica que los hogares mexicanos prefieren que ellas se ocupen en actividades no agropecuarias asalariadas. Rodríguez y Muñoz (2015) señalan que la modificación de los patrones de consumo en un contexto de ingresos limitados por los bajos salarios en el espacio rural hace imprescindible la participación de más miembros del hogar, por lo que el hogar debe hacer uso de la fuerza de trabajo de reserva, constituida por mujeres, con la finalidad de aumentar el ingreso familiar. En contraste, Ruben y Van Den Berg (2001) señalan que para el caso de Honduras los hogares con mayor número de mujeres incrementan su probabilidad de que alguna de ellas se involucre en el empleo no agropecuario por cuenta propia. Una mayor riqueza acumulada incrementa la probabilidad de dedicarse al autoempleo no agropecuario, efecto ligado con los requerimientos de inversión inicial. A diferencia del caso del empleo no agropecuario asalariado, la posesión de activos físicos agropecuarios no incide en la participación en autoempleo no agropecuario.

Respecto a las características de la localidad, es posible señalar que los servicios financieros y los de comunicación y transporte se asocian con una mayor probabilidad de realizar actividades no agropecuarias por cuenta propia, resultado presente en los coeficientes reportados en la Tabla 5 para las variables servicios de la localidad y tiempo. Por último, al considerar la sur-sureste como la región de referencia, en las demás regiones se reduce la probabilidad de que las mujeres se ocupen en actividades no agropecuarias por cuenta propia, efecto que también sucede para los hombres en las regiones noroeste y noreste. En esta misma dirección, Yúnez et al. (2015) señalan que en la región sur-sureste los hogares tienen más probabilidad de autoemplearse en actividades no agropecuarias. 
TABLA 5

Resultados del modelo logístico de datos panel: participación por sexo en el sector no agropecuario cuenta propia - 2002-2007

\begin{tabular}{|c|c|c|c|c|c|c|c|c|}
\hline \multirow{4}{*}{ Participación } & \multicolumn{8}{|c|}{ Empleo no agropecuario cuenta propia } \\
\hline & \multicolumn{4}{|c|}{ Mujeres } & \multicolumn{4}{|c|}{ Hombres } \\
\hline & \multirow{2}{*}{$\begin{array}{l}\text { Efecto } \\
\text { marginal }\end{array}$} & \multirow{2}{*}{$\begin{array}{l}\text { Valor } \\
\text { (z) }\end{array}$} & \multicolumn{2}{|c|}{$\begin{array}{l}\text { Intervalo de } \\
\text { confianza }\end{array}$} & \multirow{2}{*}{$\begin{array}{l}\text { Efecto } \\
\text { marginal }\end{array}$} & \multirow{2}{*}{$\begin{array}{l}\text { Valor } \\
\text { (z) }\end{array}$} & \multicolumn{2}{|c|}{$\begin{array}{l}\text { Intervalo de } \\
\text { confianza }\end{array}$} \\
\hline & & & $\begin{array}{l}\text { Límite } \\
\text { inferior }\end{array}$ & $\begin{array}{l}\text { Límite } \\
\text { superior }\end{array}$ & & & $\begin{array}{l}\text { Límite } \\
\text { inferior }\end{array}$ & $\begin{array}{l}\text { Límite } \\
\text { superior }\end{array}$ \\
\hline Experiencia & 0,25 & $2,81^{\star \star \star}$ & 0,074 & 0,416 & 0,18 & $3,08^{\star * \star}$ & 0,065 & 0,293 \\
\hline Experiencia al cuadrado & $-0,002$ & $-1,36$ & $-0,005$ & 0,001 & 0,00 & $-2,03^{\star \star}$ & $-0,004$ & 0,000 \\
\hline Lengua indígena & 1,00 & 0,97 & $-1,022$ & 3,025 & $-0,62$ & $-1,19$ & $-1,636$ & 0,397 \\
\hline Estado civil (casado(a)=1) & $-0,65$ & $-1,09$ & $-1,823$ & 0,518 & $-0,98$ & $-1,82$ & $-2,032$ & 0,074 \\
\hline Primaria1 (1-3 años) & 2,90 & 1,26 & $-1,628$ & 7,432 & 0,87 & 0,75 & $-1,402$ & 3,145 \\
\hline Primaria2 (4-6 años) & 3,66 & 1,67 & $-0,635$ & 7,947 & 0,99 & 0,83 & $-1,359$ & 3,346 \\
\hline Secundaria (7-9 años) & 4,85 & 1,48 & $-1,570$ & 11,276 & 1,08 & 0,73 & $-1,803$ & 3,964 \\
\hline Bachillerato (10-12 años) & 3,55 & 0,95 & $-3,785$ & 10,885 & 1,77 & 0,8 & $-2,550$ & 6,083 \\
\hline Licenciatura (> 12 años) & 3,24 & 0,67 & $-6,176$ & 12,647 & 1,10 & 0,44 & $-3,753$ & 5,950 \\
\hline $\begin{array}{l}\text { Promedio de escolaridad por } \\
\text { hogar }\end{array}$ & 0,42 & $2,50 \star \star$ & 0,092 & 0,757 & 0,46 & $3,02^{\star \star \star}$ & 0,163 & 0,764 \\
\hline $\begin{array}{l}\text { Número de mujeres de } 12 \text { años } \\
\text { y más }\end{array}$ & $-0,74$ & $-2,82^{\star \star \star}$ & $-1,249$ & $-0,225$ & $-0,47$ & $-2,52^{\star \star}$ & $-0,841$ & $-0,106$ \\
\hline Número de niños < 6 años & 0,23 & 0,83 & $-0,319$ & 0,784 & $-0,09$ & $-0,4$ & $-0,531$ & 0,352 \\
\hline Número de adultos > 65 años & $-0,74$ & $-1,27$ & $-1,878$ & 0,404 & $-1,77$ & $-3,01^{\star \star \star}$ & $-2,918$ & $-0,618$ \\
\hline Migrantes en México & 0,27 & 1,08 & $-0,221$ & 0,757 & $-0,31$ & $-1,5$ & $-0,714$ & 0,096 \\
\hline Migrantes en Estados Unidos & $-0,59$ & $-1,80$ & $-1,236$ & 0,052 & $-0,48$ & $-1,91$ & $-0,968$ & 0,013 \\
\hline Índice de riqueza & 0,70 & $3,36^{\star \star \star}$ & 0,293 & 1,111 & 0,43 & $2,68^{\star \star}$ & 0,116 & 0,748 \\
\hline Tierra agrícola & $-0,82$ & $-1,20$ & $-2,157$ & 0,521 & $-0,11$ & $-0,26$ & $-0,978$ & 0,751 \\
\hline Propiedad de ganado & $-0,24$ & $-0,39$ & $-1,464$ & 0,974 & $-0,48$ & $-1,17$ & $-1,278$ & 0,321 \\
\hline Crédito formal & 0,59 & 0,84 & $-0,797$ & 1,984 & $-0,36$ & $-0,87$ & $-1,168$ & 0,447 \\
\hline $\begin{array}{l}\text { Transferencias del gobierno } \\
\text { (Procampo) }\end{array}$ & 1,22 & 1,62 & $-0,258$ & 2,706 & 0,57 & 1,14 & $-0,409$ & 1,539 \\
\hline $\begin{array}{l}\text { Transferencias del gobierno } \\
\text { (Oportunidades) }\end{array}$ & 0,87 & 1,58 & $-0,209$ & 1,943 & 0,05 & 0,13 & $-0,691$ & 0,790 \\
\hline Tiempo (minutos) & 0,002 & 0,31 & $-0,008$ & 0,011 & 0,01 & $2,27^{\star \star}$ & 0,001 & 0,015 \\
\hline Servicios en la localidad & 0,13 & $2,35^{\star *}$ & 0,021 & 0,235 & 0,07 & $2,14^{\star \star}$ & 0,006 & 0,138 \\
\hline R2 Centro & $-3,42$ & $-3,64^{\star \star \star}$ & $-5,270$ & $-1,578$ & $-0,61$ & $-1,04$ & $-1,768$ & 0,542 \\
\hline R3 Centro-occidente & $-2,08$ & $-2,79^{\star \star \star}$ & $-3,549$ & $-0,618$ & $-0,50$ & $-0,74$ & $-1,838$ & 0,833 \\
\hline R4 Noroeste & $-4,44$ & $-4,06^{\star \star \star}$ & $-6,582$ & $-2,299$ & $-1,84$ & $-3,09^{\star \star \star}$ & $-3,013$ & $-0,674$ \\
\hline R5 Noreste & $-2,27$ & $-3,18^{\star \star \star}$ & $-3,666$ & $-0,869$ & $-1,13$ & $-1,93^{\star \star}$ & $-2,284$ & 0,018 \\
\hline Wald Chi2 & 103,60 & & & & 107,30 & & & \\
\hline Log-likelihood ratio & $-888,818$ & & & & $-929,395$ & & & \\
\hline Tamaño de muestra & 2662 & & & & 3614 & & & \\
\hline
\end{tabular}

Fuente: Elaboración propia con datos de la ENHRUM I y II.

Nota: ${ }^{\star \star \star}$ significativos a $1 \%,{ }^{* \star}$ significativos a $5 \%$.

La región de referencia es la sur-sureste. 


\section{Conclusiones}

El sector rural mexicano ha experimentado importantes cambios sociodemográficos y económicos en las últimas décadas, entre ellos, la creciente importancia relativa de las actividades y del ingreso no agropecuario en el ingreso de los hogares rurales, el aumento relativo de la participación de las mujeres tanto en actividades no agropecuarias por cuenta propia como asalariadas y un aumento en el nivel de escolaridad del hogar y de la migración, lo que ha llevado a una reestructuración económica y social de lo que conocemos como espacios rurales.

La brecha laboral por género sitúa a las mujeres con tasas inferiores de participación en el sector no agropecuario. No obstante, la brecha se ha reducido en el transcurso del tiempo.

El factor asociado al perfil de la mujer trabajadora en el sector no agropecuario asalariado es la educación, pues las mujeres que se insertan en el mercado de trabajo requieren de una mayor preparación académica, lo que sugiere la existencia de discriminación laboral, si consideramos que la media de años de escolaridad es similar y que de cada cuatro ocupados en el ámbito rural solo uno es mujer.

Las mujeres rurales que se incorporan al mercado de trabajo no agropecuario se caracterizan por tener un mayor nivel de escolaridad; la relación de parentesco que tienen con el jefe del hogar es el de hijas; retrasan su unión en pareja y disminuyen la natalidad. Los anteriores factores influyen en su participación en el sector no agropecuario asalariado, actividad que les permite obtener ingresos para mejorar su bienestar y el de su familia.

Por otra parte, dentro de los factores que desincentivan la participación de las mujeres uno es hablar una lengua indígena, condición que afecta negativamente las probabilidades de ocuparse en trabajos no agropecuarios asalariados. Otros factores inhibidores son estar casada, tener familiares migrantes en Estados Unidos, poseer tierra agrícola o ganado, recibir transferencias del gobierno a través del programa Oportunidades y el tiempo que lleva desplazarse a la localidad urbana más cercana. Con respecto a las transferencias públicas de tipo asistencial, el gobierno las ha reorientado hacia proyectos productivos, a pesar de lo cual es necesario enfatizar en la realización de proyectos productivos exclusivamente dirigidos a las mujeres, así como en estrategias para facilitar el desarrollo de sus capacidades.

Respecto a los factores determinantes de la participación laboral femenina en actividades no agropecuarias por cuenta propia, se encontró que inciden positivamente la experiencia, el promedio de educación de los miembros del hogar, la riqueza del hogar y los servicios disponibles en la localidad. Por otra parte, la presencia de mujeres con 12 años y más en el hogar, y dado el contexto actual de las zonas rurales en las que existen nuevos patrones de bienestar y con ingresos restringidos por los bajos salarios, se hace necesaria la participación de un mayor número de miembros del hogar en edad de trabajar, por lo que son las mujeres las que deben incursionar en el mercado laboral para contribuir al ingreso familiar. 
Los resultados confirman las hipótesis de trabajo planteadas en el documento; es decir, que un mayor nivel de escolaridad y número de mujeres en edad laboral incentivan la participación de hombres y mujeres en el sector no agropecuario asalariado. En cambio, hablar una lengua indígena restringe las posibilidades para incorporarse en este tipo de empleo.

Esta investigación aporta información inédita que contribuye a integrar propuestas de política pública tendientes a fomentar la participación de los individuos en actividades no agropecuarias. Por ejemplo, crear incentivos para que la mujer rural alcance mayores niveles de escolaridad y focalizar transferencias para que emprenda actividades productivas no agropecuarias. Lo anterior debe apoyarse con la provisión de servicios a nivel de localidad, como servicios financieros, de comunicación y transporte, además de mejorar las vías de comunicación, con la finalidad de contribuir de manera más efectiva al bienestar de las familias en el México rural.

\section{Referencias}

ABRAMO, L. ¿Inserción laboral de las mujeres en América Latina: una fuerza de trabajo secundaria? Estudos Feministas, v. 12, n. 2, p. 224-235, 2004. Disponible en: 〈http://www. redalyc.org/html/381/38112213/>. Acceso el: 3 jul. 2017.

AMUEDO-DORANTES, C.; DE LA RICA, S. Complements or substitutes? Task specialization by gender and nativity in Spain. Labour Economics, v. 18, n. 5, p. 697-707, 2011. doi: 10.1016/j. labeco.2011.02.002.

ARRIAGA, C. M.; PEDRAZA, A. M.; NAVA, E. G.; CHÁVEZ, M. C.; CASTELÁN, O. A. Livestock Agrodiversity of Mazahua Smallholder Campesino Systems in the Highlands of Central México. Human Ecology, v. 33. n. 6, p. 821-845, 2005. doi: 10.1007/s10745-005-8212-9.

BARRETT, C. B.; REARDON, T.; WEBB, P. Nonfarm income diversification and household livelihood strategies in rural Africa: concepts, dynamics, and policy implications. Food policy, v. 26, n. 4, p. 315-331, 2001. doi: 10.1016/S0306-9192(01)00014-8.

BENARÍA, L. La globalización de la economía y el trabajo de las mujeres. Revista de Economía y Sociología del Trabajo, v. 13-14, p. 49-75, 1991.

CAMERON, A.; TRIVEDI, P. K. Microeconometrics using stata, v. 5, College Station, Texas: Stata Press, 2009.

CASIQUE, I. Participación en el trabajo doméstico de hombres y mujeres en México. Papeles de población, v. 14, n. 55, p. 173-200, 2008. Disponible en: 〈http://www.scielo.org.mx/scielo. php?pid=S1405-74252008000100008\&script=sci_arttext>. Acceso el: 3 jul. 2017.

Conocimiento y uso de anticonceptivos entre los jóvenes mexicanos. El papel del género. Estudios Demográficos y Urbanos, v. 26, n. 3, p. 601-637, 2011.

CONEVAL (Consejo Nacional de Evaluación de la Política de Desarrollo Social). Informe de Evaluación de la Política de Desarrollo Social en México 2008. Disponible en: 〈http://www. coneval.org.mx/rw/resource/coneval/EVALUACIONES/2532.pdf〉. Acceso el: 3 jul. 2016.

CEPAL (Comisión Económica para América Latina y el Caribe); FAO (Organización de las Naciones Unidas para la Alimentación y la Agricultura); IICA (Instituto Interamericano de Cooperación para la Agricultura). Perspectivas de la agricultura y del desarrollo rural en las Américas: una mirada hacia América Latina y el Caribe. San José, Costa Rica, 2014. 
CEPAL (Comisión Económica para América Latina y el Caribe); OIT (Organización Internacional del Trabajo); FAO (Organización de las Naciones Unidas para la Alimentación y la Agricultura). Políticas de mercado de trabajo y pobreza rural en América Latina: Tomo I. Roma, Italia, 2012.

COOPER, A. J. Disparidad en el mercado laboral: ¿Cómo lograr la igualdad entre hombres y mujeres? En 40 años, 40 respuestas, Ideas para la democratización del mundo del trabajo. México: Fundación Friedrich Ebert en México, 2009. p. 205-210.

CHRISTOFIDES, N.; POLYCARPOU, A.; VRACHIMIS, K. Gender wage gaps, sticky floors and glass ceilings in Europe. Labour Economics, v. 21, p. 86-102, 2013. doi: 10.1016/j.labeco.2013.01.003.

DE JANVRY, A.; SADOULET, E. Income strategies among rural households in Mexico: the role of off-farm activities. World development, v. 29, n. 3, p. 467-480, 2001. doi: 10.1016/S0305750X(00)00113-3.

DE OLIVEIRA, O.; ARIZA, M. Trabajo femenino en América Latina: un recuento de los principales enfoques analíticos. En: DE LA GARZA TOLEDO, E. (Coord.). Tratado latinoamericano de sociología del trabajo. México: El Colegio de México-Flacso-UAM-FCE, 2000. p. 644-663.

DEERE, C. ¿La feminización de la agricultura? Asalariadas, campesinas y reestructuración económica en la América Latina rural. ALASRU: Análisis Latinoamericano del medio rural, v. 4, p. 77-136, 2006.

DEERE, C. D.; LEÓN, M. The gender asset gap: land in Latin America. World Development, v. 31, n. 6, p. 925-947, 2003. doi: 10.1016/S0305-750X(03)00046-9.

DIRVEN, M. El empleo rural no agrícola y la disminución de la pobreza rural ¿Qué sabemos en América Latina en 2010? Santiago, Chile: Rimisp, 2011 (Documento de trabajo, 2. Proyecto conocimiento y cambio en pobreza rural y desarrollo). Disponible en: <http://www20.iadb.org/ intal/catalogo/PE/2011/08363.pdf>. Acceso el: 3 jul. 2017.

DOMÍNGUEZ, V.; BROWN, F. Diferencias de género en la elección del sitio de trabajo en un contexto de crisis. Revista CEPAL, n. 111, p. 83-102, 2013. Disponible en: 〈http://repositorio.cepal.org/ bitstream/handle/11362/35934/RVE111DominguezBrown_es.pdf?sequence=1\&isAllowed=y . Acceso el: 3 jul. 2017.

ELLIS, F. Household strategies and rural livelihood diversification. Journal of Development Studies, v. 35, n. 1, p. 1-38, 1998.

ENHRUM I. Encuesta Nacional a Hogares Rurales de México. El Colegio de México y Desarrollo y Alimentación Sustentable A. C., 2002. Disponible en: 〈http://bdsocial.inmujeres.gob.mx/ index.php/enhrum-36/encuesta-nacional-a-hogares-rurales-de-mexico>. Acceso el: 3 jul. 2017.

ENHRUM II. Encuesta Nacional a Hogares Rurales de México. El Colegio de México y Desarrollo y Alimentación Sustentable A. C., 2007.

ESCALANTE, R.; CATALÁN, H.; GALINDO, L. M.; REYES, O. Desagrarización en México: tendencias actuales y retos hacia el futuro. Cuadernos de Desarrollo Rural, v. 59, p. 87-116, 2007. Disponible en: 〈http://www.redalyc.org/html/117/11759004/〉. Acceso el: 3 jul. 2017.

ESPINO, A. Economía feminista: enfoques y propuestas. Montevideo: FCEA, Universidad de la República, 2010 (Serie Documentos de Trabajo DT 5/10).

FAWAZ, Y.; RODRÍGUEZ, C. Mujeres rurales y trabajo en Chile central. Actitudes, factores y significaciones. Cuadernos de Desarrollo Rural, v. 10, n. 72, p. 47-68, 2013. Disponible en: 〈http:// www.scielo.org.co/pdf/cudr/v10n72/v10n72a04.pdf〉. Acceso el: 3 jul. 2017.

FAWAZ, J.; SOTO, P. Mujer, trabajo y familia. Tensiones, rupturas y continuidades en sectores rurales de Chile central. Revista de Estudios de Género La Ventana, v. 4, n. 35, p. 218-254, 2012. Disponible en: 〈http://www.scielo.org.mx/scielo.php?pid=S140594362012000100009\&script=sci_arttext\&tlng=pt>. Acceso el: 3 jul. 2017. 
FIDA (Fondo Internacional de Desarrollo Agrícola). Política del FIDA sobre la igualdad de género y el empoderamiento de la mujer. Roma: FIDA, 2012. Disponible en: 〈https://www.ifad.org/ documents/10180/a7fae734-7a43-443d-ab25-884b4629ff5è. Acceso el: 3 jul. 2017.

FILMER, D.; PRITCHETT, L., H. Estimating wealth effects without expenditure data - or tears: an application to educational enrollments in states of India. Demography, v. 38, n. 1, p. 115-132, 2001. doi: 10.1353/dem.2001.0003.

FLATØ, M.; MUTTARAK, R.; PELSER, A. Women, weather and woes: the triangular dynamics of female-headed households, economic vulnerability and climate variability in South Africa. World Development, v. 90. p. 41-62, 2017. doi: 10.1016/j.worlddev.2016.08.015.

GARAY, S. Trabajo agropecuario y no agropecuario de las mujeres rurales en México, 20002010. Notas de Población, v. 98, p. 125-162, 2014. Disponible en: 〈http://repositorio.cepal.org/ handle/11362/37711). Acceso el: 3 jul. 2017.

GARCíA, B. Reestructuración económica y feminización del mercado de trabajo en México. Papeles de población, v. 7, n. 27, p. 45-61, 2001. Disponible en: 〈http://www.scielo.org.mx/ scielo.php?pid=S1405-74252001000100004\&script=sci_arttext\&tlng=en〉. Acceso el: 3 jul. 2017.

GÓMEZ, O. L. Caso de México. In: FAIGUENBAUM, S.; ORTEGA, C.; BAQUERO, F. S. (Coord.). Pobreza rural y políticas públicas en América Latina y el Caribe. Santiago, Chile: FAO, Tomo I, 2013.

GREENSTEIN, T. N. Economic dependence, gender, and the division of labor in the home: a replication and extension. Journal of Marriage and Family, v. 62, n. 2, p. 322-335, 2000.

INEGI (Instituto Nacional de Estadística y Geografía). Encuesta Nacional de Ocupación y Empleo (ENOE 2006). 2006. Disponible en: 〈http://www.beta.inegi.org.mx/proyectos/enchogares/ regulares/enoe/>. Acceso el: 4 sep. 2015.

Encuesta Nacional de Ocupación y Empleo (ENOE). 2014a. Disponible en: 〈http:// www.beta.inegi.org.mx/proyectos/enchogares/regulares/enoe/>. Acceso el: 4 sep. 2015.

Encuesta Nacional de Ingresos y Gastos de los Hogares. 2014b. Disponible en: 〈http://www.beta.inegi.org.mx/proyectos/enchogares/regulares/enoe/〉. Acceso el: 8 sep. 2015.

. Encuesta Nacional de Ocupación y Empleo (ENOE). 2015. Disponible en: 〈http://www. beta.inegi.org.mx/proyectos/enchogares/regulares/enoe/>. Acceso el: 11 sep. 2015.

INMUJERES (Instituto Nacional de las Mujeres). Incorporación de la dimensión de género en la medición multidimensional de la pobreza. Ciudad de México: INMUJERES, 2015 (Cuaderno de trabajo, n. 57).

JONASSON, E.; HELFAND, S. M. How important are locational characteristics for rural nonagricultural employment? Lessons from Brazil. World Development, v. 38, n. 5, p. 727-741, 2010.

JUÁREZ, X. Dreams and miseries of the mexican migration. Tesis (Doctorado) - University of California Davis, Estados Unidos, 2013.

KABEER, N. Gender equality, economic growth, and women's agency: the "endless variety" and "monotonous similarity" of patriarchal constraints. Feminist Economics, v. 22, n. 1, p. 295-321, 2016. doi: 10.1080/13545701.2015.1090009

KAY, C. Estudios rurales en América Latina en el periodo de globalización neoliberal: ¿una nueva ruralidad? Revista Mexicana de Sociología, v. 71, n. 4, p. 607-645, 2009. Disponible en: 〈http:// www.scielo.org.mx/scielo.php?pid=S0188-25032009000400001\&script=sci_arttext\&tlng=pt〉. Acceso el: 3 jul. 2017. 
KLASEN, S.; LAMANNA, F. The impact of gender inequality in education and employment on economic growth: new evidence for a panel of countries. Feminist Economics, v. 15, n. 3, p. 91132, 2009. doi: 10.1080/13545700902893106.

KLASEN, S.; LECHTENFELD, T.; POVEL, F. A feminization of vulnerability? Female headship, poverty, and vulnerability in Thailand and Vietnam. World Development, v. 71, p. 36-53, 2015. doi: 10.1016/j.worlddev.2013.11.003.

LANJOUW, J.; O.; LANJOUW, P. The rural non-farm sector: issues and evidence from developing countries. Agricultural Economics, v. 26, n. 1, p. 1-23, 2001. doi: 10.1111/j.1574-0862.2001. tb00051.x.

MARTÍNEZ-DOMÍNGUEZ, M. El papel del empleo no agropecuario como estrategia de diversificación de ingresos en hogares rurales de México. Tesis (Doctorado) - El Colegio de Postgraduados, México, 2015.

MINCER, J. A. Schooling and earnings. Schooling, experience, and earnings. Columbia University Press, NBER, 1974. p. 41-63.

NJUKI, J.; SANGINGA, P. C. Women livestock ownership and markets. Bridging the gender gap in Eastern and Southern Africa. Londres-Nueva York: Earthscan Routledge, 2013.

OOSTENDORP, R. Globalization and the gender wage gap. The World Bank Economic Review, v. 23, n. 1, p. 141-161, 2009. doi: 10.1093/wber/lhn022.

ORTEGA, L. Las relaciones de género entre la población rural del Ecuador, Guatemala y México. Santiago, Chile: CEPAL, 2012 (Serie mujer y desarrollo, n. 121).

OSORIO, C. La emergencia de género en la nueva ruralidad. Revista Punto Género, n. 1, p.153-169, 2011. doi: 10.5354/0719-0417.2011.16851.

PEDRERO, N. M. Las condiciones de trabajo en los años noventa en México. Las mujeres y los hombres: ¿ganaron o perdieron? Revista Mexicana de Sociología, v. 65. n. 4, p. 733-761, 2003. Disponible en: 〈http://www.scielo.org.mx/scielo.php?script=sci_arttext\&pid =S0188-25032003000400001〉. Acceso el: 3 jul. 2017.

PLOEG, V. D.; ROEP, D. Multifunctionality and rural development: the actual situation in Europe. In: VAN HUYLENBROECK, G.; DURAND, G. Multifunctional agriculture; a new paradigm for European agriculture and rural development. Hampshire, England: Ashgate Publishers, 2003. p. 37-53.

REARDON, T.; BERDEGUÉ, J.; ESCOBAL, G. Rural nonfarm employment and incomes in Latin America: overview and policy implications. World Development, v. 29. n. 3, p. 395-409, 2001. doi: 10.1016/S0305-750X(00)00112-1.

REARDON, T.; BERDEGUÉ, J.; BARRETT, C. B.; STAMOULIS, K. Household income diversification into rural nonfarm activities. In: REARDON, T.; HAGGBLADE, S.; HAZELL, P. (Ed.). Transforming the rural nonfarm economy: opportunities and threats in the developing world. Baltimore: Johns Hopkins University Press, 2007. p. 115-140.

RODRÍGUEZ, C.; MUÑOZ, J. Participación laboral de las mujeres rurales chilenas: tendencias, perfiles y factores predictores. Cuadernos de Desarrollo Rural, v. 12, n. 75, p. 77-98, 2015. Disponible en: 〈http://search.proquest.com/openview/a89aa807ac1035eb59879caa5a388d8 b/1?pq-origsite=gscholar\&cbl=2041079>. Acceso el: 3 jul. 2017.

ROJAS, O. Género, organización familiar y trabajo extradoméstico femenino asalariado y por cuenta propia. Revista Latinoamericana de Estudios de la Familia, v. 2, p. 31-50, 2010. Disponible en: 〈http://revlatinofamilia.ucaldas.edu.co/downloads/Rlef2_(completa).pdf\#page=31〉. Acceso el: 3 jul. 2017.

RUBEN, R.; VAN DEN BERG, M. Nonfarm employment and poverty alleviation of rural farm households in Honduras. World Development, v. 29, n. 3, p. 549-560, 2001. doi: 10.1016/S0305750X(00)00107-8. 
SOSA, V.; ROMÁN, R. P. Participación y tiempo en actividades cotidianas de hombres y mujeres vinculados al mercado laboral en México. Sociedad y Economía, v. 29, p. 63-89, 2015. Disponible en: 〈http://sociedadyeconomia.univalle.edu.co/index.php/sye/article/view/3375/3297〉. Acceso el: 3 jul. 2017.

SU, W.; ERIKSSON, T.; ZHANG, L.; BAI, Y. Off-farm employment and time allocation in on-farm work in rural China from gender perspective. China Economic Review, v. 41, p. 34-45, 2016. doi: 10.1016/j.chieco.2016.08.006.

TANWIR, M.; SAFDAR, T. The rural woman's constraint to participation in rural organizations. Journal of International Women's Studies, v. 14, n. 3, p. 210-229, 2013.

VALDÉS, X. Desincronización temporal y espacial entre trabajo y familia: hacerse el salario en las migraciones estacionales de los/as temporeros/as de la uva. Revista Polis, v. 11, n. 31, p. 449-476, 2012. doi: 10.4067/S0718-65682012000100024.

VALENZUELA, J. P.; DURYEA, S. Examinando la prominente posición de Chile a nivel mundial en cuanto a desigualdad de ingresos: comparaciones regionales. Estudios de Economía, v. 38, n. 1, p. 259-293, 2011. doi: 10.4067/S0718-52862011000100011.

WIGGINS, S. y HAZELL, P. Access to rural non-farm employment and enterprise development. Background paper for the IFAD Rural Poverty Report, 2011. Disponible en: <https://www.ifad.org/ documents/10180/9946bdef-fbaa-44b5-b30a-cad26d953fd3>, Acceso el: 3 jul. 2017.

YÚNEZ, N. A.; TAYLOR, J. E. The determinants of nonfarm activities and incomes of rural households in México with emphasis on education. World Development, v. 29, n. 3, p. 561-572, 2001. doi: 10.1016/S0305-750X(00)00108-X.

YÚNEZ, N. A.; RIVERA, R. F.; CHÁVEZ, A. M. A.; MORA, R. J.; TAYLOR, J. E. La economía del campo mexicano: tendencias y retos para su desarrollo. Ciudad de México: El Colegio de México, 2015.

ZHAO, J.; BARRY, P. J. Income diversification of rural households in China. Canadian Journal of Agricultural Economics, v. 62, n. 3, p. 307-324, 2014. doi: 10.1111/cjag.12033

\section{Sobre los autores}

Jorge Mora-Rivera es profesor-investigador del Tecnológico de Monterrey, campus Ciudad de México (ITESM-CCM).

Marlen Martínez Domínguez es investigadora Cátedras-Conacyt en el Centro de Investigación e Innovación en Tecnologías de la Información y Comunicación (INFOTEC).

José Luis Jaramillo Villanueva es profesor-investigador en el Colegio de Postgraduados.

María de los Ángeles Chávez Alvarado es candidata a doctora en Economía por la Universidad de Siena, Italia.

\section{Dirección para correspondencia}

Jorge Mora-Rivera

Tecnológico de Monterrey

Calle del Puente \# 222 Col. Ejidos de Huipulco, Tlalpan

CP 14380 - Ciudad de México, México.

Marlen Martínez Domínguez

Centro de Investigación e Innovación en Tecnologías de la Información y Comunicación (INFOTEC) Circuito Tecnopolo Sur 112, Col. Fraccionamiento Tecnopolo Pocitos

CP 20313 - Aguascalientes, Ags, México. 


\author{
José Luis Jaramillo Villanueva \\ Colegio de Postgraduados \\ Carretera Federal México-Puebla Km. 125.5, Santiago Momoxpan \\ CP 72760 - Puebla, México. \\ María de los Ángeles Chávez Alvarado \\ Desarrollo y Alimentación Sustentable (DAS) \\ Av. Universidad 1855 (401), Oxtopulco \\ CP 04318 - Coyoacaán, Ciudad de México, México
}

\title{
Resumo
}

Participação no setor não agrícola no México rural: uma perspectiva de gênero

As famílias rurais diversificam sua renda como estratégia para minimizar o risco, reduzir a variabilidade e garantir um nível mínimo de renda. Com informações da Encuesta Nacional a Hogares Rurales de México, o presente estudo examinou, sob uma perspectiva de gênero, os fatores que determinam a participação no setor não agrícola. Os resultados indicam que, nas ocupações assalariadas não agrícolas, os homens participam com baixos níveis de escolaridade e a situação indígena limita a incorporação de ambos os sexos. Em atividades de autoemprego não agrícola, são essenciais a riqueza acumulada das famílias e serviços financeiros, de comunicação e transporte.

Palavras-chave: Gênero. Emprego não agrícola. Famílias rurais. México.

\section{Abstract}

Participation in the non-agricultural sector in rural Mexico: a gender perspective

Rural households diversify their income as a strategy to minimize risk, reduce variability and ensure a minimum level of income. With information panel of the National Rural Household Survey of Mexico, this study examined under a gender perspective, the factors that determine participation in the non-agricultural sector. The results indicate that employed in non-agricultural occupations, men participate with lower levels of education and indigenous status limits the incorporation of both genders. In non-agricultural self-employment activities are essential household accumulated wealth and financial services, communication and transportation.

Keywords: Gender. Non-agricultural employment. Rural households. Mexico. 
